\title{
Exergy Analysis of Absorption Power Cycle Depending on Source Temperatures
}

\author{
Kyoung Hoon Kim
}

\begin{abstract}
The absorption power generation systems using ammonia-water mixture as a working fluid are proven to be the feasible method for utilizing a low-temperature heat source in the form of sensible energy. In this paper, an exergy analysis is carried out for an absorption power generation system of Kalina cycle using ammonia-water mixture as the working fluid for efficient conversion of low-temperature heat source. Effects of the ammonia mass fraction and the heat source temperature are parametrically investigated on the exergy destruction of each component of the system and the exergy efficiency of the system. Results show that the exergetical performance is greatly affected by the heat source temperature and the ammonia mass fraction of the working fluid.
\end{abstract}

Index Terms-Ammonia-water mixture, absorption power generation, exergy, Kalina cycle.

\section{INTRODUCTION}

The research on the conversion of low-grade heat from sources such as geothermal heat, waste heat, biogenic energy systems, low-temperature solar thermal heat, etc. into electrical power or low-temperature energy conversion has attracted more and more attention. The power generation systems using ammonia-water mixture as a working fluid instead of pure water as in the case of a steam Rankine cycle are proven to be the feasible method for utilizing a low-temperature heat source in the form of sensible energy. A major advantage for using zeotropic mixtures as a working fluid in the power generation systems instead of pure working fluids is that heat can be supplied or rejected at variable temperature but still at constant pressure [1]-[4].

Wagner et al. [5] analyzed thermodynamically an ammonia-water based Rankine cycle for renewable based power production. They showed that changes in the concentration of the ammonia-water mixture due to its nature allow thermodynamic cycles to adapt to fluctuations in renewable energy sources, which is an important advantage with respect to other working fluids. Zamfirescu and Dincer [6] presented a thermodynamic analysis of the trilateral ammonia-water Rankine cycle that does not use a boiler, but rather the saturated liquid is flashed by an expander. Kim et al. [7]-[11] investigated the characteristics of stream in the heat exchangers used in the ammonia-water based power generation cycles. They also studied the Rankine cycle using

Manuscript received April 9, 2015; revised August 8, 2015. This research was respectfully supported by Engineering Development Research Center (EDRC) funded by the Ministry of Trade, Industry \& Energy (MOTIE). (No. N0000990).

Kyoung Hoon Kim is with the Kumoh National Institute of Technology, Daehakro 61, Gumi, Gyeongbuk 730-701, Republic of Korea (e-mail: khkim@kumoh.ac.kr). ammonia-water mixture as working fluid for recovery of low-temperature waste heat, and they are compared the regenerative Rankine cycle with the simple Rankine cycle. They also carried out a thermodynamic analysis of a combined cycle using a low grade heat source and LNG cold energy.

The Kalina cycle was introduced in 1984 [12] as an alternative to the conventional Rankine cycle to be used as a bottoming cycle for combined cycle power plants. Mixture of ammonia and water is used in the cycle as its working fluid. The composition of the ammonia-water mixture could be varied by changing the ammonia mass fraction which is defined as the ratio of the mass of ammonia in the mixture to the total mass of the mixture. Since its introduction, several uses for the Kalina cycle have been proposed such as in a geothermal power plant, for waste heat recovery, and in solar power plants [13].

Ogriseck [14] performed an investigation of the integration of the Kalina cycle process in a combined heat and power generation, while Lolos and Rogdakis [15] investigated Kalina cycle using low-temperature heat sources. Bombarda et al. [16] carried out a comparative analysis on thermodynamic performance of Kalina and organic Rankine cycles. Ganesh and Srinivas [17] investigated a lowtemperature Kalina cycle to optimize the heat recovery from solar collectors. Arslan [18], [19] presented exergo-economic evaluation and optimization study of Kalina cycle using geothermal resources. Sun et al. [20] studied a solar boosted Kalina cycle with an auxiliary superheater. They also performed energy-exergy analysis and parameter design optimization of the KCS-11 solar system with an auxiliary superheater [21]. Kim [22] carried out a thermodynamic performance analysis for a Kalina cycle using ammonia-water mixture as a working fluid for efficient conversion of low-temperature heat source in the form of sensible energy.

The exergy analysis based on the second law is well suited for furthering the goal of more effective energy resources use, for it enables the location, cause, and true magnitude of waste and lost to be determined [23]. Exergy is a measure of the departure of the state of a system from that of the environment, and the method of exergy analysis is well suited for furthering the goal of more energy resource use, for it enables the location, cause, and true magnitude of waste and loss to be determined [24], [25].

This study presents an exergy analysis for a Kalina cycle using ammonia-water mixture as a working fluid for efficient recovery of low-grade heat source. The effects of the source temperature and the ammonia mass fraction on the exergy destruction of each component of the system and the exergy efficiency of the system are parametrically investigated. 


\section{SySTEM ANALYSIS}

In this work an exergetical analysis is carried out for a Kalina cycle using ammonia-water mixture as the working fluid for recovery of a low-temperature heat source in the form of sensible energy to useful work. The schematic diagram of the system is shown in Fig. 1. Let the temperatures of source and coolant be $T_{s}$ and $T_{c}$, respectively, and the basic ammonia mass fraction at pump or condenser be $x_{b}$. In the cycle the working fluid which comes out the condenser as a saturated liquid at temperature $T_{L}$ of state 1 is compressed with a pump to pressure of $P_{H}$ of state 2 , and preheated in a regenerator to state 3 . Then the fluid is further heated in the source heat exchanger to the turbine inlet temperature $T_{H}$ of state 4 and then separated in the separator into a saturated vapor of state 5 and a saturated liquid of state 7 . The vapor of state 5 from the separator enters the turbine and produces useful work during the expansion in the turbine to the condensing pressure of state 6 . The liquid of state 7 from the separator enters the regenerator and heats the mixture of state 2 exiting the pump to state 6 , while it is cooled down to state 8 , and then it is expanded in a throttle valve to state 9 . The fluids of state 6 and state 9 are mixed in a mixer and enter the condenser with state 10 [7], [22].

Important assumptions in the present cycle analysis are as follows: (1) The pressure and temperature at the turbine inlet are $P_{H}$ and $T_{H}$, respectively. (2) The mixture at the condenser outlet is saturated liquid at $T_{L}$. (3) Temperature differences between hot and cold streams in the heat exchangers are equal to a prescribed pinch temperature difference, $\Delta T_{p p}$. (4) Pressure variations except the turbine and pump are also negligible. (5) The performances of pump and turbine are characterized by constant isentropic efficiencies of $\eta_{p}$ and $\eta_{t}$, respectively.

Then, the mixture temperature at which the minimum temperature difference occurs and the exit temperature of the source under the conditions of maximum mass flow rate can be determined by the following equation [7].

$$
\min _{T} \Delta T\left(T, T_{s, \text { out }}\right)-\Delta T_{p p}=0
$$

And the mass flow rates of $m_{6}$ and $m_{9}$ can be determined from the mass conservation at the separator and the enthalpies of $h_{3}$ and $h_{8}$ are evaluated from the equation of energy balance.

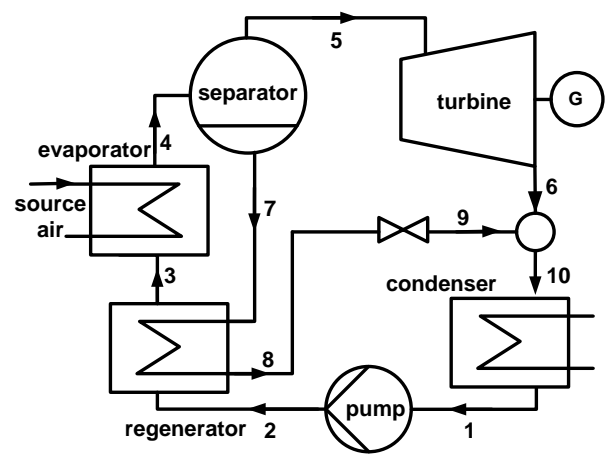

Fig. 1. Schematic diagram of the system.

The turbine power $W_{t}$, pumping power $W_{p}$, and net power production of the system $W_{\text {net }}$ can be obtained as:

$$
\begin{gathered}
W_{t}=m_{5}\left(h_{5}-h_{6}\right) \\
W_{p}=m_{1}\left(h_{2}-h_{1}\right) \\
W_{\text {net }}=W_{t}-W_{p}
\end{gathered}
$$

where $h$ is the specific enthalpy.

Exergy is a measure of the maximum capacity of a system to perform useful work as it proceeds to a specified final state in equilibrium with its surrounding and exergy analysis has been proven to be a very effective way of analyzing and optimizing the complex power generation systems [23]. The rate of exergy flow $E$ is evaluated as

$$
E=m\left[h-h_{0}-T_{0}\left(s-s_{0}\right)\right]
$$

where $m$ is the mass flow rate, $h$ and $s$ are respectively the specific enthalpy and entropy, and the subscript 0 refers to the dead state.

The exergy input $E_{s}$ and total exergy destruction (or anergy) including exergy losses $D_{\text {tot }}$ can be evaluated as follows.

$$
\begin{gathered}
E_{s}=m_{s} c_{s}\left\{T_{s}-T_{0}-T_{0} \ln \left(T_{s} / T_{0}\right)\right\} \\
D_{\text {tot }}=E_{s}-W_{\text {net }}
\end{gathered}
$$

where $W_{\text {net }}$ is the net power production of the system.

The exergy efficiency $\eta_{e x}$ is defined as the ratio of net power production to the total exergy input to the system, and the second law efficiency $\eta_{\mathrm{II}}$ is defined as the ratio of net power production to the net exergy input to the system as follows:

$$
\begin{gathered}
\eta_{e x}=W_{\text {net }} / E_{s} \\
\eta_{\Pi}=W_{\text {net }} /\left(E_{s}-E_{\text {sout }}\right)
\end{gathered}
$$

where subscript sout indicates the state of source exhaust.

Let us define the exergy destruction ratio (anergy ratio) of a component as the ratio of the exergy destruction of the component to the total exergy input. The anergy ratios of the system can be evaluated as follows;

$$
\begin{gathered}
\text { Source exhaust: } D S E=E_{\text {sout }} / E_{s} \\
\text { Coolant exhaust: } D C E=E_{\text {cout }} / E_{s} \\
\text { Evaporator: } D E V=\left(E_{s}+E_{3}-E_{\text {sout }}-E_{4}\right) / E_{s} \\
\text { Regenerator: } D R G=\left(E_{2}+E_{7}-E_{3}-E_{8}\right) / E_{s} \\
\text { Condenser: } D C D=\left(E_{c}+E_{10}-E_{\text {cout }}-E_{1}\right) / E_{s} \\
\text { Turbine: } D T B=\left(E_{5}-E_{6}-W_{t}\right) / E_{s}
\end{gathered}
$$




$$
\begin{gathered}
\text { Pump: } D P M=\left(E_{1}-E_{2}+W_{p}\right) / E_{s} \\
\text { Valve: } D V L=\left(E_{8}-E_{9}\right) / E_{s} \\
\text { Mixer: } D M X=\left(E_{6}+E_{9}-E_{10}\right) / E_{s}
\end{gathered}
$$

Then sum of the exergy destruction ratios of the system and the exergy efficiency becomes unity [24]-[26].

$$
\begin{gathered}
\eta_{e x}+D S E+D C E+D E V+D R G+D C D \\
+D T B+D P M+D V L+D M X=1
\end{gathered}
$$

In this paper, thermodynamic properties of liquid and vapor phase of the ammonia-water mixture are evaluated by using the Gibbs free energy;

$$
G^{E} / R T=x(1-x)\left[F_{1}+F_{2}(2 x-1)+F_{3}(2 x-1)^{2}\right]
$$

Here, $x$ is the mole fraction of ammonia in the mixture, and $F_{1}, F_{2}$, and $F_{3}$ are the functions of temperature and pressure [27]. The equilibrium states of liquid and vapor phase are calculated using the modeling of [7];

$$
\begin{gathered}
\mu_{a}^{L}=\left(\frac{\partial G_{m}^{L}}{\partial N_{a}}\right)_{T, P, N_{w}}=\left(\frac{\partial G_{m}^{g}}{\partial N_{a}}\right)_{T, P, N_{w}}=\mu_{a}^{g} \\
\mu_{w}^{L}=\left(\frac{\partial G_{m}^{L}}{\partial N_{w}}\right)_{T, P, N_{a}}=\left(\frac{\partial G_{m}^{g}}{\partial N_{w}}\right)_{T, P, N_{a}}=\mu_{w}^{g}
\end{gathered}
$$

Here, $N_{a}, N_{w}$, and $N$ are numbers of moles of ammonia, water, and the mixture, respectively.

\section{RESULTS AND DISCUSSIONS}

In this work it is assumed that the source fluid is a standard air and the mass flow rate of the source fluid is $1 \mathrm{~kg} / \mathrm{s}$. The basic data of the system variables are as follows; separator pressure $P_{H}=20 \mathrm{bar}$, condensation temperature $T_{L}=25^{\circ} \mathrm{C}$, coolant temperature $T_{c}=15^{\circ} \mathrm{C}$, pinch temperature difference $\Delta T_{p p}=5^{\circ} \mathrm{C}$, isentropic pump efficiency $\eta_{p}=0.85$, isentropic turbine efficiency $\eta_{t}=0.90$, quality limit at turbine exit $y_{t}=$ 0.90. The key parameters in this study are the source temperature and the ammonia mass fraction. It is assumed that the separator temperature is lower than the source temperature by $20^{\circ} \mathrm{C}$ [22].

Fig. 2 shows the effects of source temperature on the anergy of the exhausted source for various ammonia mass fractions. The anergy of exhausted source also indicates the exergy loss by exhausted source fluid. It can be seen from the figure that for a specified pressure there may exists a lower limit of allowable source temperature especially for low ammonia mass fractions and the lower limit of source temperature decreases with increasing ammonia mass fraction. It is because for the separation of the working fluid into liquid and vapor in the separator, the separator temperature should be higher than the bubble point of the ammonia-water mixture and the bubble point decreases with increasing ammonia mass fraction for a given pressure. The anergy ratio decreases with increasing source temperature for a given ammonia mass fraction. It occurs because as the source temperature increases, the exergy input by the source fluid increases but the source exhaust temperature remains almost constant. When the ammonia mass fraction increases for a given source temperature, the anergy ratio decreases with increasing ammonia concentration. This is because the temperature at which the pinch point occurs inside the heat exchanger decreases with higher ammonia mass fraction, which then leads to lowering of the temperature of exhausted source.

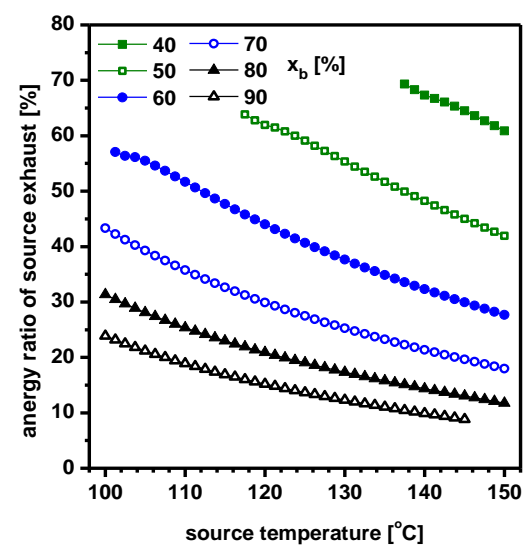

Fig. 2. Effects of source temperature on anergy ratio of exhausted source for various ammonia mass fractions.

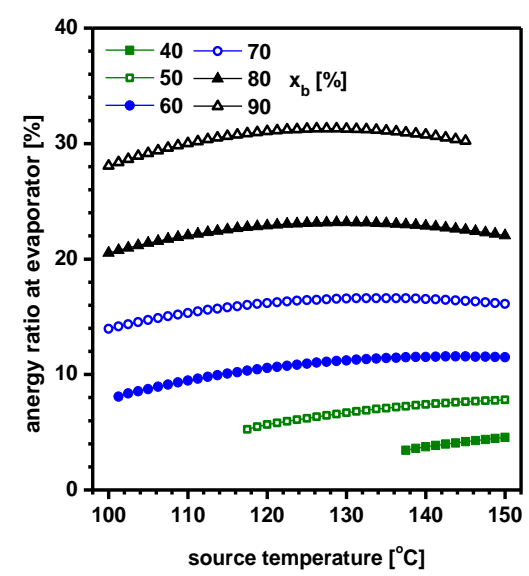

Fig. 3. Effects of source temperature on anergy ratio of evaporator for various ammonia mass fractions.

Anergy ratios of evaporator are plotted against source temperature in Fig. 3 for various ammonia mass fractions. As source temperature increases for a given ammonia mass fraction, the heat transfer in the evaporator as well as the exergy input by the source fluid increase, thus there are both the increasing and decreasing factors for the anergy ratio of the evaporator. So the anergy ratio has a peak with respect to the source temperature for a given ammonia mass fraction. The source temperature for the peak value increases with decreasing ammonia mass fraction, so the anergy ratio monotonically increases with source temperature for low ammonia mass fractions for the range of the source temperature. The anergy ratio decreases with increasing ammonia mass fraction for a given source temperature. It 
occurs because as the ammonia mass fraction increases, the thermodynamic properties of the mixture approaches to those of pure ammonia, the average temperature difference between the hot and cold fluid streams in the evaporator is expected to grow, so the irreversibility in the evaporator increases substantially.

The change of the anergy ratio of condenser to varying source temperature is depicted in Fig. 4. As source temperature increases for a specified ammonia mass fraction, the anergy ratio increases, due to the increase in the heat transfer in the condenser. For a given source temperature, the anergy ratio increases first and reach a peak point and then starts to decreases as the ammonia mass fraction increases. This is because as the ammonia mass fraction increases, the average temperature difference between the streams becomes larger, and consequently the anergy ratio increases. However, when the ammonia mass fraction becomes higher and working fluid is closer to pure ammonia, temperature of the mixture remains nearly constant inside the condenser, which makes the average temperature difference between the fluid streams and consequently the anergy smaller [8].

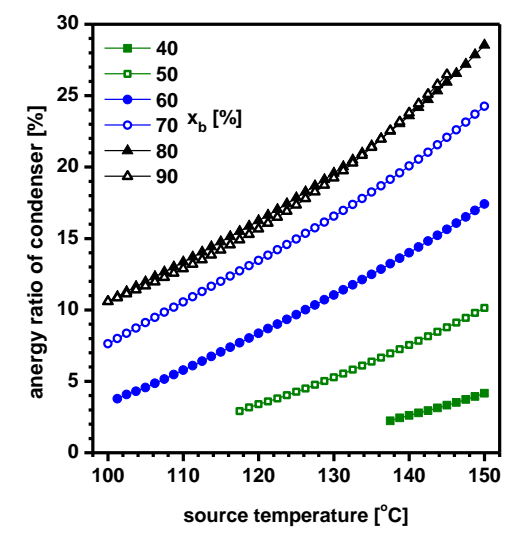

Fig. 4. Effects of source temperature on anergy ratio of condenser for various ammonia mass fractions.

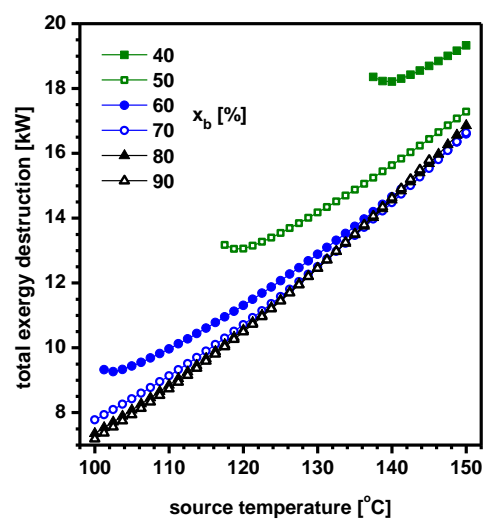

Fig. 5. Effects of source temperature on total anergy for various ammonia mass fractions.

Effects of source temperature on the total anergy are illustrated in Fig. 5 for various ammonia mass fractions. As the source temperature increases for a specified ammonia mass fraction, the total exergy destruction increases due to increase in the temperature differences between hot and cold streams in the heat exchangers. For a given source temperature, the anergy ratio has a peak value with respect to the ammonia mass fraction.

Fig. 6 and Fig. 7 show the effects of source temperature on the exergy and second law efficiencies, respectively, for various ammonia mass fractions. Exergy efficiency is defined as the ratio of the net power production to the exergy input as Eq. (5). When the source temperature increases for a given ammonia mass fraction, not only the net power production but also the exergy input by the source fluid increase, therefore there are both the increasing and decreasing factors for the exergy efficiency. So the exergy efficiency has generally a peak with respect to the source temperature for a given ammonia mass fraction. The source temperature for the peak value increases with decreasing ammonia mass fraction, so the exergy efficiency simply increases with source temperature for low ammonia mass fractions for the range of the source temperature.

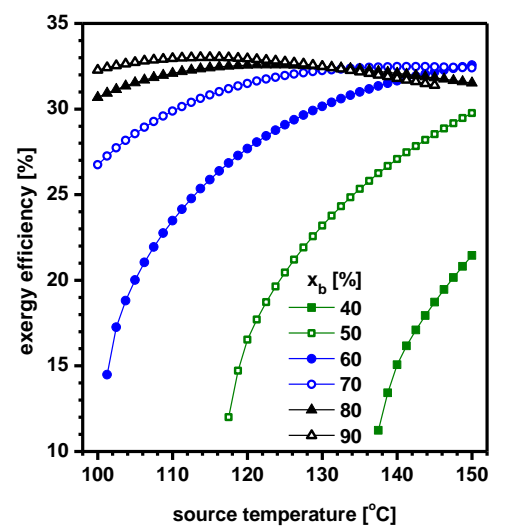

Fig. 6. Effects of source temperature on the exergy efficiency for various ammonia mass fractions.

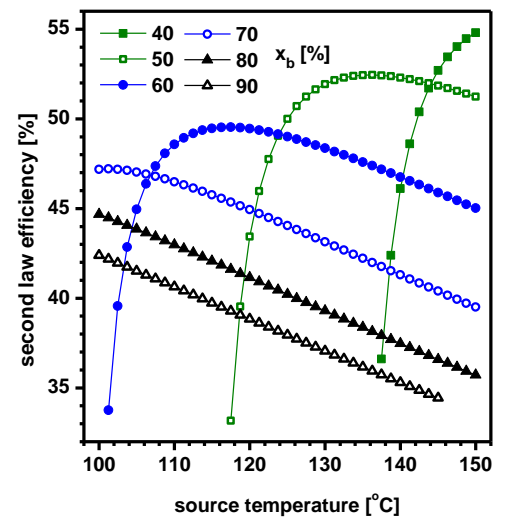

Fig. 7. Effects of source temperature on the second law efficiency for various ammonia mass fractions.

On the other hand, the second law efficiency is defined as the ratio of the net power production to the net exergy input which is the difference between the exergy input and the exergy exhaust of the source fluid, as is seen in Eq. (6). Since the net exergy input is smaller than the exergy input, the second law efficiency is higher than the exergy efficiency. The second law efficiency has generally a peak with respect to the source temperature for a given ammonia mass fraction and the source temperature for the peak value increases with decreasing ammonia mass fraction, which is similar to the exergy efficiency. However, the source temperature for the peak of the second law efficiency is lower than that of the exergy efficiency, thus the second law efficiency simply decreases with increasing source temperature for high ammonia mass fractions for the range of the source temperature. 


\section{CONCLUSIONS}

In this paper an exergetical performance analysis was carried for an absorption power generation cycle using ammonia-water mixture as a working fluid in order to produce maximum power from the low-temperature heat source in the form of sensible energy. Special attention is focused on the effects of the source temperature as well as the ammonia mass fraction on the exergetical system performance such as exergy destructions of source exhaust, evaporator, condenser as well as the exergy and the second law efficiencies.

Results show that the exergetical performance of the system is sensitively influenced by the source temperature as well as the ammonia mass fraction of the working fluid. The biggest anergy occurs due to the source exhaust for the low ammonia mass fraction but occurs at the evaporator for high ammonia mass fraction. The performance characteristics of the exergy efficiency due to variations of ammonia mass fraction and source temperature are much different from those of the second-law efficiency, which requires further investigations.

\section{REFERENCES}

[1] O. M. Ibrahim and S. A. Klein, “Absorption power cycle," Energy, vol. 21, pp. 21-27, 1996.

[2] O. M. Ibrahim, "Design considerations for ammonia-water Rankine cycle," Energy, vol. 21, pp. 835-841, 1996.

[3] B. Kiani, A. Akisawa, and T. Kashiwagi, "Thermodynamic analysis of load-leveling hyper energy converting and utilization system," Energy, vol. 33, pp. 400-409, 2008.

[4] P. Roy, M. Désilets, N. Galanis, H. Nesreddine, and E. Cayer, "Thermodynamic analysis of a power cycle using a low-temperature source and a binary NH3-H2O mixture as working fluid," Int. J. Therm. Sci., vol. 49, pp. 48-58, 2010.

[5] W. R. Wagar, C. Zamfirescu, and I. Dincer, "Thermodynamic performance assessment of an ammonia-water Rankine cycle for power and heat production," Energy Convers. Manage., vol. 51, pp. 2501-2510, 2010.

[6] C. Zamfirescu and I. Dincer, "Thermodynamic analysis of a novel ammonia-water trilateral Rankine cycle," Thermochimica. Acta., vol. 477, pp. 7-15, 2008.

[7] K. H. Kim, C. H. Han, and K. Kim, "Effects of ammonia concentration on the thermodynamic performances of ammonia-water based power cycles," Thermochimica. Acta., vol. 530, pp. 7-16, 2012.

[8] K. H. Kim, C. H. Han, and K. Kim, "Comparative exergy analysis of ammonia-water based Rankine cycles with and without regeneration," Int. J. Exergy, vol. 12, pp. 344-361, 2013.

[9] K. H. Kim, H. J. Ko, and K. Kim, "Assessment of pinch point characteristics in heat exchangers and condensers of ammonia-water based power cycles," Applied Energy, vol. 113, pp. 970-981, 2014.

[10] K. H. Kim, K. Kim, and H. J. Ko, "Entropy and exergy analysis of a heat recovery vapor generator for ammonia-water mixtures," Entropy, vol. 16, pp. 2056-2070, 2014.
[11] K. H. Kim and K. C. Kim, "Thermodynamic performance analysis of a combined power cycle using low grade heat source and LNG cold energy," App. Therm. Eng., vol. 70, pp. 50-60, 2014.

[12] A. I. Kalina, "Combined-cycle system with novel bottoming cycle," $J$. Eng. Gas Turbines Power, vol. 106, pp. 737-742, 1984.

[13] A. Modi and F. Haglind, "Thermodynamic optimization and analysis of four Kalina cycle layouts for high temperature applications," Appl. Therm. Eng., vol. 76, pp. 196-205, 2015.

[14] S. Ogriseck, "Integration of Kalina cycle in a combined heat and power plant, a case study," Appl. Therm. Eng., vol. 29, pp. 2843-2848, 2009.

[15] P. A. Lolos and E. D. Rogdakis, "A Kalina power cycle driven by renewable energy sources," Energy, vol. 34, pp. 457-464, 2009.

[16] P. Bombarda, C. M. Invernizzi, and C. Pietra, "Heat recovery from Diesel engines: A thermodynamic comparison between Kalina and ORC cycles," Appl. Therm. Eng., vol. 30, pp. 212-219, 2010.

[17] N. S. Ganesh and T. Srinivas, "Design and modeling of low temperature solar thermal power station," Applied Energy, vol. 91, pp. 180-186, 2012.

[18] O. Arslan, "Exergoeconomic evaluation of electricity generation by the medium temperature geothermal resources, using a Kalina cycle: Simav case study," Int. J. Therm. Sci., vol. 49, pp. 1866-1873, 2010.

[19] O. Arslan, "Power generation from medium temperature geothermal resources: ANN-based optimization of Kalina system-34," Energy, vol. 36, pp. 2528-2534, 2011.

[20] F. Sun, Y. Ikegami, and B. Jia, "A study on Kalina solar system with an auxiliary superheater," Renewable Energy, vol. 41, pp. 210-219, 2012.

[21] F. Sun, W. Zhou, Y. Ikegami, K. Nakagami, and X. Su, "Energy-exergy analysis and optimization of the solar-boosted Kalina cycle system 11 (KCS-11)," Renewable Energy, vol. 66, pp. 268-279, 2014.

[22] K. H. Kim, "Performance analysis of absorption power cycle under different source temperatures," Int. J. Mech. Aero. Ind. Mech. Eng., vol. 9, pp. 249-252, 2015.

[23] A. Bejan, Advanced Engineering Thermodynamics, 3rd ed. New York, NY, USA: John Wiley \& Sons, 2006.

[24] C. H. Han and K. H. Kim, "Exergetical analysis of organic flash cycle with two-phase expander for recovery of finite thermal reservoirs," $J$. Therm. Sci., vo1. 23, pp. 572-579, 2014.

[25] K. H. Kim, "Exergy analysis of organic Rankine cycle with LNG as its heat sink for recovery of low grade heat source," Wulfenia Journal, vol. 22, pp. 117-126, 2015.

[26] K. H. Kim and K. Kim, "Comparative analyses of energy-exergyentransy for the optimization of heat-work conversion in power generation systems," Int. J. Heat Mass Transfer, vol. 84, pp. 80-90, 2015.

[27] F. Xu and D. Y. Goswami, "Thermodynamic properties of ammonia-water mixtures for power cycle," Energy, vol. 24, pp. 525-536, 1999.

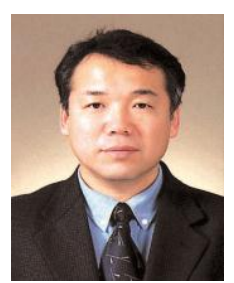

Kyoung Hoon Kim received the $\mathrm{PhD}$ degree in mechanical engineering from Korea Advanced Institute of Science and Technology (KAIST). He is currently a professor in the Department of Mechanical Engineering at Kumoh National Institute of Technology, Korea. His research interests are in the areas of modeling and design of energy systems. 